\title{
The recommendations of a consensus panel for the screening, diagnosis, and treatment of neurogenic orthostatic hypotension and associated supine hypertension
}

\author{
Christopher H. Gibbons ${ }^{1}$ - Peter Schmidt ${ }^{2}$ - Italo Biaggioni ${ }^{3}$ - Camille Frazier-Mills ${ }^{4}$. \\ Roy Freeman ${ }^{1} \cdot$ Stuart Isaacson $^{5} \cdot$ Beverly Karabin $^{6} \cdot$ Louis Kuritzky $^{7}$ •

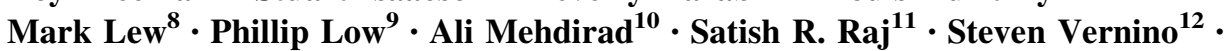 \\ Horacio Kaufmann ${ }^{13}$
}

Received: 11 November 2016/Revised: 19 December 2016/Accepted: 20 December 2016/Published online: 3 January 2017 (C) The Author(s) 2016. This article is published with open access at Springerlink.com

\begin{abstract}
Neurogenic orthostatic hypotension (nOH) is common in patients with neurodegenerative disorders such as Parkinson's disease, multiple system atrophy, pure autonomic failure, dementia with Lewy bodies, and peripheral neuropathies including amyloid or diabetic neuropathy. Due to the frequency of $\mathrm{nOH}$ in the aging population, clinicians need to be well informed about its diagnosis and management. To date, studies of nOH have used different outcome measures and various methods of diagnosis, thereby preventing the generation of evidencebased guidelines to direct clinicians towards 'best practices' when treating patients with $\mathrm{nOH}$ and associated supine hypertension. To address these issues, the American Autonomic Society and the National Parkinson Foundation initiated a project to develop a statement of recommendations beginning with a consensus panel meeting in Boston on November 7, 2015, with continued communications and contributions to the recommendations through October of
\end{abstract}

Electronic supplementary material The online version of this article (doi:10.1007/s00415-016-8375-x) contains supplementary material, which is available to authorized users.

Christopher H. Gibbons

cgibbons@bidmc.harvard.edu

1 Harvard Medical School and Beth Israel Deaconess Medical Center, Boston, MA, USA

2 National Parkinson Foundation, Miami, FL, USA

3 Vanderbilt University Medical Center, Nashville, TN, USA

4 Duke University Hospital and Central Carolina Hospital, Durham, NC, USA

5 Parkinson's Disease and Movement Disorders Center of Boca Raton, Boca Raton, FL, USA

6 University of Toledo Medical Center, Toledo, OH, USA
2016. This paper summarizes the panel members' discussions held during the initial meeting along with continued deliberations among the panel members and provides essential recommendations based upon best available evidence as well as expert opinion for the (1) screening, (2) diagnosis, (3) treatment of $\mathrm{nOH}$, and (4) diagnosis and treatment of associated supine hypertension.

Keywords Neurogenic orthostatic hypotension · Supine hypertension - Autonomic dysfunction - Droxidopa · Midodrine $\cdot$ Fludrocortisone

\section{Introduction}

Neurogenic orthostatic hypotension $(\mathrm{nOH})$ is a prevalent disorder [1,2]. Clinicians from a variety of specialties need to be well informed about diagnosis and management of $\mathrm{nOH}$ as it carries a significant burden of morbidity and has also been associated with increased mortality [3-5]. Clinicians should, therefore, familiarize themselves with this condition and evolving management options, which offer substantial

7 University of Florida College of Medicine, Gainesville, FL, USA

8 Keck/USC School of Medicine, Los Angeles, CA, USA

9 Mayo Clinic, Rochester, MN, USA

10 Saint Louis University Hospital, St. Louis, MO, USA

11 University of Calgary, Calgary, BC, Canada

12 University of Texas Southwestern Medical Center, Dallas, TX, USA

13 New York University Langone Medical Center, New York, NY, USA 
symptomatic improvement. This communication will focus primarily on $\mathrm{nOH}$, while recognizing that orthostatic symptoms are often multifactorial: i.e., patients with $\mathrm{nOH}$ may have their symptoms worsened by medications, hypovolemia, intrinsic cardiovascular disease, and other factors $[6,7]$.

The literature on $\mathrm{nOH}$ is fraught with inconsistencies in the definition and methods of diagnosis, and suffers from a lack of evidence-based guidelines to direct clinicians towards 'best practice'. As nOH is a subset of orthostatic hypotension $(\mathrm{OH})$, it should be noted that patients with $\mathrm{nOH}$ and $\mathrm{OH}$ may experience the same symptoms but for different reasons. The following consensus definition of $\mathrm{OH}$ was devised by the American Autonomic Society and the American Academy of Neurology, and endorsed by the European Federation of Autonomic Societies and the World Federation of Neurology: $\mathrm{OH}$ is " .... a sustained reduction of systolic blood pressure of at least $20 \mathrm{mmHg}$ or diastolic blood pressure of $10 \mathrm{mmHg}$, or both, within $3 \mathrm{~min}$ of standing or head-up tilt to at least $60^{\circ}$ on a tilt table" [8]. In addition to meeting the definition for $\mathrm{OH}$, patients with $\mathrm{nOH}$ have impairment of the autonomic nervous system that is characterized by failure to provide adequate autonomic postural responses, most prominently systemic vasoconstriction and a compensatory increase in heart rate sufficient to maintain blood pressure. This deficit is, in large part, attributed to insufficient norepinephrine release from sympathetic nerves [9]. In addition, many patients with $\mathrm{nOH}$ also suffer from supine hypertension, which further confounds therapy because pharmacologic treatments to normalize standing blood pressure may worsen supine hypertension [10]. Differences in study designs and endpoints, as well as a paucity of data, preclude achieving definitive evidencebased treatment regimens through a systematic review of trials [11-22]. To move forward in an effective and safe manner, consensus is required on the basics of screening, diagnosing, and treating patients with $\mathrm{nOH}$. Thus, an expert opinion statement to these basic approaches is needed.

To address this issue, the American Autonomic Society and the National Parkinson Foundation jointly held an initial consensus panel meeting to formulate essential recommendations into a working guideline for the screening, diagnosis, and treatment of $\mathrm{nOH}$ and associated supine hypertension. Results of the discussions held during the meeting, along with continued deliberations among the panel participants are presented here along with recommendations in each of the topic areas. Whereas most patients with disorders typically associated with $\mathrm{nOH}$ are seen by cardiologists or neurologists, particularly movement disorder specialists, the first point of contact and potential for identification of $\mathrm{nOH}$ is with the primary care clinicians. Hence, the following consensus commentary is meant to provide guidance for all clinicians who might encounter and/or ultimately manage $\mathrm{nOH}$.

\section{Screening for $\mathrm{nOH}$}

There is no standardized or recommended screening protocol for patients that present with symptoms of orthostatic hypotension. Presenting symptoms and signs of $\mathrm{OH}$ include postural lightheadedness or dizziness, the sensation of blacking out, and falls with or without syncope. Less common symptoms include orthostatic cognitive dysfunction (executive function worsens significantly during the orthostatic challenge in patients with autonomic dysfunction, possibly because of transient frontal lobe hypoperfusion), mental dulling, generalized weakness, neck pain or discomfort in the suboccipital and paracervical region ('coat hanger' configuration - a manifestation of hypotension-induced ischemia of the strap muscles of the neck), or platypnea (dyspnea while standing due to $\mathrm{OH}$ causing inadequate perfusion of ventilated lung apices or ventilation perfusion mismatch) [23-27]. Thus, screening for $\mathrm{nOH}$ starts with questions to identify the symptoms of $\mathrm{OH}$ followed by measurement of blood pressures from the supine (or seated) to standing position (recommended specific technique for timing of blood pressure measurements is detailed below) [6]. It may be beneficial if screening questionnaires and blood pressure measurements are conducted by a qualified non-physician (such as a nurse) prior to the patient's visit with the clinician. Patients in the following five categories need to be routinely screened for $\mathrm{OH}$ :

(1) Patients suspected of, or diagnosed with any neurodegenerative disorder associated with autonomic dysfunction, including Parkinson's Disease (PD), Multiple System Atrophy (MSA), Pure Autonomic Failure (PAF), or Dementia with Lewy Bodies (DLB);

(2) Patients who have reported an unexplained fall or have had an episode of syncope;

(3) Patients with peripheral neuropathies known to be associated with autonomic dysfunction (e.g., diabetes, amyloidosis, HIV);

(4) Patients who are elderly ( $\geq 70$ years of age) [28] and frail or on multiple medications;

(5) Patients with postural (orthostatic) dizziness or nonspecific symptoms that only occur when standing.

Patients in each of these groups have a higher risk of $\mathrm{OH} / \mathrm{nOH}$ when compared to the normal population [29].

For these five categories of patients, clinicians should ask about cardinal symptoms of $\mathrm{OH}$, their frequency and severity, how long they can stand, and the effect of symptoms on their activities of daily living. Questions about symptoms should also note the time of day when the symptoms occur, as symptoms of $\mathrm{OH} / \mathrm{nOH}$ are most likely to occur in the morning and after meals [30-32]. A more complete list of questions to use when screening patients for $\mathrm{OH} / \mathrm{nOH}$ is presented in 
Table 1 Screening questions for suspected $\mathrm{OH} / \mathrm{nOH}$

\begin{tabular}{ll}
\hline Question & Screening questions* \\
\hline 1 & Have you fainted/blacked out recently? \\
2 & Do you feel dizzy or lightheaded upon standing? \\
3 & Do you have vision disturbances when standing? \\
4 & Do you have difficulty breathing when standing? \\
5 & Do you have leg buckling or leg weakness when standing? \\
6 & Do you ever experience neck pain or aching when \\
7 & standing? \\
8 & Do the above symptoms improve or disappear when you \\
& Are the above symptoms worse in the morning or after \\
9 & meals? \\
10 & Have you experienced a fall recently? \\
& Are there any other symptoms you commonly experience \\
& when you stand up or within $3-5$ min of standing and \\
\end{tabular}

* Any positive response should prompt further investigation with orthostatic blood pressure measurements

Table 1. If a patient gives a positive response to one or more of the questions listed in Table 1, they should be considered as being at risk for $\mathrm{OH} / \mathrm{nOH}$ and a more complete evaluation including orthostatic vital signs needs to be conducted to confirm a diagnosis of $\mathrm{OH} / \mathrm{nOH}$. From a practical standpoint, at the minimum, the patient should be asked a variation of question 10 "Do you have symptoms when you stand up or within 3-5 min of standing and get better when you sit or lay down?" Because falls are of such consequence to aging patients, a specific question about circumstances of falls is appropriate. Clinicians must recognize that some patients are reluctant to admit symptoms of $\mathrm{OH}$ or falls, fearing that they may lose their autonomy due to family member insistence on enhancing their safety.

\section{Diagnosis of $\mathrm{nOH}$ in individuals who screen positive for $\mathrm{OH}$}

After screening to identify a patient as being at risk for $\mathrm{OH}$, an accurate assessment of the underlying cause(s) is required to determine the appropriate treatment recommendation. A stepwise approach is recommended for diagnosis of nOH, specifically starting with measurement of orthostatic blood pressure and heart rate, followed by more detailed autonomic testing in select cases (Fig. 1).
Fig. 1 Stepwise approach to the diagnosis of $\mathrm{nOH}$

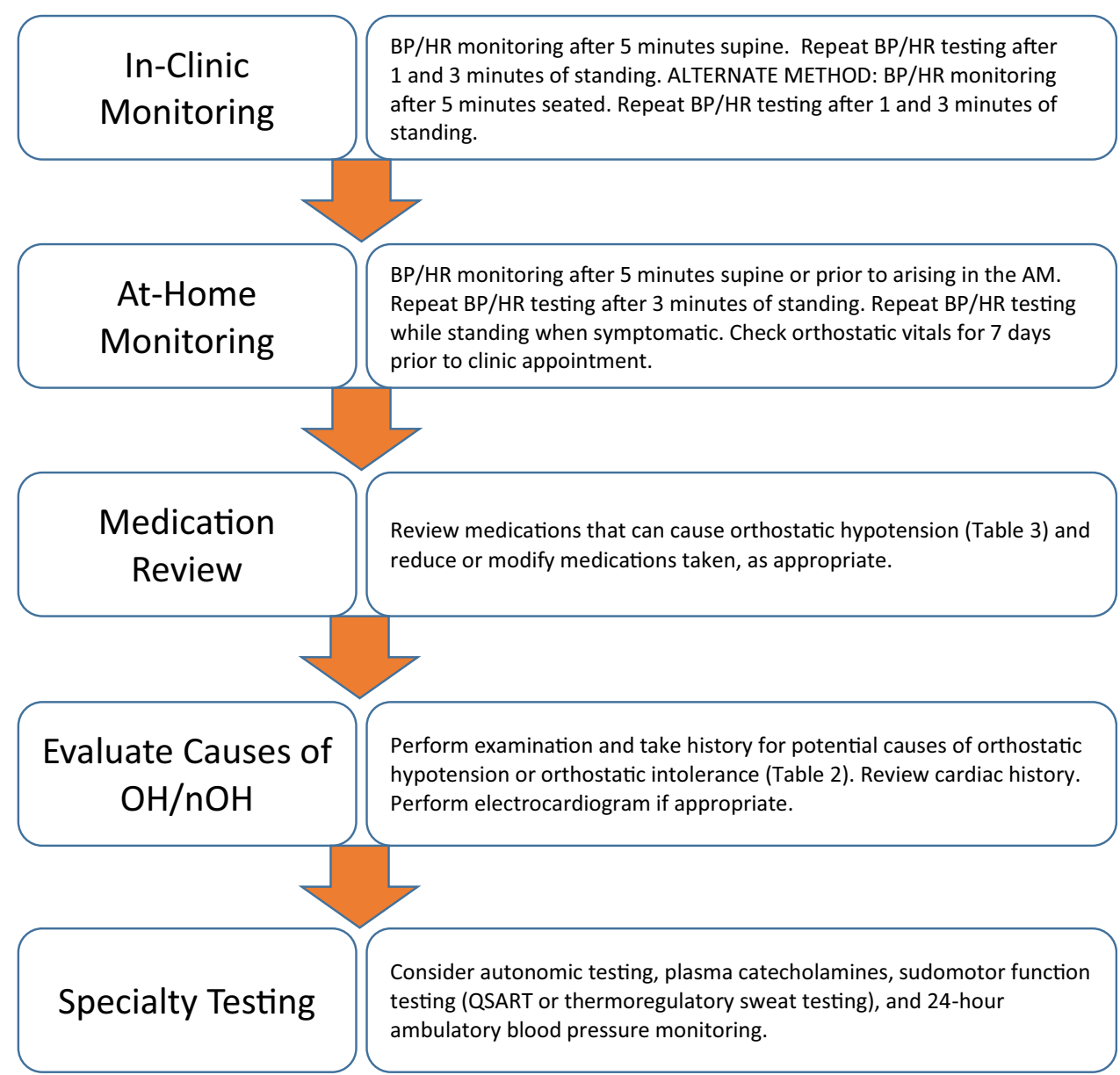




\section{Diagnostic tests for $\mathrm{nOH}$}

\section{Blood pressure testing}

The hallmark test for $\mathrm{OH}$ is measurement of change in blood pressure from supine, after at least $5 \mathrm{~min}$ of rest, to standing (or head-up tilt [HUT]) [33]. Current guidelines define $\mathrm{OH}$ as a sustained fall of systolic blood pressure of at least $20 \mathrm{mmHg}$ or a diastolic blood pressure of $10 \mathrm{mmHg}$ within $3 \mathrm{~min}$ of standing (or HUT) [8]. However, in patients with supine hypertension (a supine systolic blood pressure $\geq 150 \mathrm{mmHg}$ or diastolic blood pressure $\geq 90 \mathrm{mmHg}$ ), a $30 \mathrm{mmHg}$ decrease in systolic blood pressure or 15-point fall in diastolic blood pressure may be a more appropriate criterion for patients with $\mathrm{nOH}$ as the magnitude of blood pressure fall is dependent on the baseline blood pressure [8].

\section{A practical stepwise approach to orthostatic blood pressure and heart rate testing}

In-clinic monitoring of blood pressure and heart rate The recommended gold standard measurement of $\mathrm{OH}$ includes having patients rest in the supine position for at least $5 \mathrm{~min}$ and then stand for $3 \mathrm{~min}$, with blood pressure measurements taken just prior to standing and at both 1 and $3 \mathrm{~min}$ of standing [33]. However, in facilities in which this method is impractical, a seated-to-standing blood pressure can be performed as an acceptable alternative. In the alternative method, patients sit for at least $5 \mathrm{~min}$ and then stand for $3 \mathrm{~min}$, with blood pressure measured just prior to standing and at 1 and $3 \mathrm{~min}$ of standing. If the test is positive (i.e., $\geq 20 / 10 \mathrm{mmHg}$ decline in blood pressure with standing), the subject has $\mathrm{OH}$. However, if the test is negative but symptoms are strongly suggestive of $\mathrm{OH}$, a supine-to-standing blood pressure test (or HUT) should be considered. As some individuals with $\mathrm{OH}$ are at risk for falls when standing suddenly, testing staff should be aware of this possibility and take appropriate precautions.

Even this appropriate testing of blood pressure will not identify all patients with $\mathrm{OH}$, since variability in meals, hydration, time of day, and medications can affect the orthostatic change in blood pressure. Additionally, there is a subgroup of patients who manifest symptoms of $\mathrm{OH}$ beyond the 3-min interval, defined as delayed $\mathrm{OH}$ [34], which may be a manifestation of early autonomic failure. Further discussion of this group is outside the scope of this paper.

Upon standing from a supine or seated position, healthy, normally volume-replete individuals will typically experience a modest decline in systolic blood pressure $(<10 \mathrm{mmHg})$, a very slight increase in diastolic blood pressure (approximately $2.5 \mathrm{mmHg}$ ) and a modest increase in heart rate (10-20 beats per minute [bpm]) [6]. These compensatory changes are induced primarily by augmentation of norepinephrine output by sympathetic autonomic peripheral nerve endings. Measuring the heart rate change from the supine (and/or seated) to standing may aid in differentiating between $\mathrm{nOH}$ and $\mathrm{OH}$ [35]. If an individual develops $\mathrm{OH}$ upon standing, an increase in heart rate of $<15$ bpm suggests a diagnosis of $\mathrm{nOH}$. In contrast, individuals with non-neurogenic $\mathrm{OH}$ will typically demonstrate an increase in heart rate of $>15 \mathrm{bpm}$ within $3 \mathrm{~min}$ of standing [7, 36]. The heart rate information is acquired during the measurement of orthostatic vital signs as described above. It should be noted that without a fall in blood pressure, the heart rate criteria for nOH do not apply. In addition, monitoring of postural heart rate changes for diagnostic purposes requires that there is no confounding medication effect (e.g., beta blockers, alpha-beta blockers, non-dihydropyridine calcium channel blockers; see below) or intrinsic cardiac rhythm disturbances (e.g., sick sinus syndrome, complete heart block, dependence on a mechanical pacemaker) that prevent a compensatory heart rate increase upon standing. In a similar fashion, volume depletion (e.g., diuretics) in healthy individuals can be associated with $\mathrm{OH}$, but should not be confused with $\mathrm{nOH}$ because there will still be an exaggerated increase in heart rate upon standing $(\geq 20 \mathrm{bpm})$ in $\mathrm{OH}$, contrasted with an expected failure to increase heart rate in $\mathrm{nOH}$.

At-home monitoring of blood pressure and heart rate In addition to in-clinic blood pressure monitoring, patients should be asked to check their blood pressure and heart rate at home and record the values in a diary. We recommend that patients or their caregivers check blood pressures at home in the supine position (at least $15 \mathrm{~min}$ after laying down at bedtime or prior to arising from bed in the morning) and after $3 \mathrm{~min}$ of standing (with assistance as necessary) after arising from bed in the morning. The following timings are our recommendations for at-home blood pressures and heart rate monitoring: (1) first thing in the morning before taking morning medications, (2) when a patient feels symptomatic, and (3) at bedtime for several days. We recommend that patients keep a blood pressure and heart rate diary for at least 7 days preceding a clinic visit, but after having a clinic visit patients should not need to measure blood pressure and heart rate on a continuous daily basis unless a change in therapy occurs. With any change in therapy, an additional week of blood pressure monitoring is required to determine the effectiveness of the change. (An example patient diary for blood pressure and heart rate is provided in Appendix I.)

Medication review There are numerous medications that can diminish the normal compensatory postural increase in heart rate, (e.g., beta blockers, non-dihydropyridine 
calcium channel blockers, combined beta-/alpha-blockers such as carvedilol, central alpha-2 agonists such as clonidine or guanfacine, and antiarrhythmic agents such as amiodarone).

Exclude other causes of $\mathrm{OH} / \mathrm{nOH}$ If blood pressure and heart rate changes indicate $\mathrm{OH} / \mathrm{nOH}$, a complete history and physical examination, as well as electrocardiogram and laboratory testing, should be focused on ruling out nonneurogenic causes of $\mathrm{OH}$, including cardiogenic, vascular, or iatrogenic etiologies $[6,7]$. Table 2 lists recommended tests to conduct when evaluating a patient for $\mathrm{OH} / \mathrm{nOH}$. Cardiac disorders (e.g., pacemakers, dysrhythmias, ablation, etc.) can preclude heart rate augmentation [37]; therefore, a cardiac history, an electrocardiogram, and medication review (as noted above) should consistently be performed. Due to variability among patients, including age, disease status, and current medication usage, the lack of heart rate increase on standing may not always be an accurate indicator of $\mathrm{nOH}$ in patients with $\mathrm{OH}$; therefore, clinical scenario and specific presentation need to be considered.

Specialty testing If standard orthostatic blood pressure testing does not reveal $\mathrm{OH}$ in an at-risk individual with unexplained postural symptoms, falls, or syncope, then any of the following are appropriate as next steps: (1) conducting extended at-home blood pressure monitoring with results recorded by the patient or caregiver, (2) implementing 24-h ambulatory blood pressure monitoring where the patient can annotate times when supine or standing (to determine a typical range of blood pressures during the day and, with patient annotation of position, help to understand fluctuations), or (3) use of autonomic function tests. Some individuals may develop delayed $\mathrm{OH}$ later than 3 min of standing, which can be identified with prolonged standing blood pressures, or prolonged tilt table testing (HUT) [34, 38].

The specialized tests described below are considered by the panel to be beyond the scope of many primary care clinicians and usually require referral to a center specializing in autonomic disorders. Specialized tests for a definitive diagnosis of $\mathrm{nOH}$ include autonomic reflex testing (including heart rate variability to paced breathing, heart rate and blood pressure response to a Valsalva maneuver, and continuous blood pressure response to a prolonged HUT). Other tests used to help diagnose nOH may include plasma fractionated catecholamine levels and/ or sudomotor function testing.

These specialized tests may be helpful in confirming the diagnosis of $\mathrm{nOH}$ by demonstrating baroreflex dysfunction based on HUT testing with beat-to-beat blood pressure measurement, and/or the beat-to-beat blood pressure and heart rate response to the Valsalva maneuver [39]. In addition, cardiovascular reflex testing, tilt table testing, and the Valsalva maneuver may help discriminate multiple system atrophy with predominant parkinsonism (MSA-P) from PD [40]. Supine and standing plasma fractionated catecholamine levels can aid in making a diagnosis, but have somewhat low sensitivity [6, 41]. At-home, 24-h blood pressure monitoring may be helpful not only to discern hypotensive episodes throughout the day (as long

Table 2 Recommended initial testing to evaluate individuals presenting with $\mathrm{OH} / \mathrm{nOH}$

\begin{tabular}{|c|c|}
\hline Test & Function in $\mathrm{OH} / \mathrm{nOH}$ differential diagnosis \\
\hline Electrocardiogram & To evaluate cardiac electrical activity \\
\hline Complete blood count (CBC) & To evaluate for anemia, or infection that could contribute to non-neurogenic $\mathrm{OH}$ \\
\hline $\begin{array}{l}\text { Basic metabolic panel (sodium, potassium, chloride, bicarbonate, } \\
\text { blood urea nitrogen, creatinine and fasting glucose) }\end{array}$ & $\begin{array}{l}\text { To look for hypo/hypernatremia, hypo/hyperkalemia, acid-base disorders, blood } \\
\text { volume depletion (BUN:Cr ratio }>20 \mathrm{mg} / \mathrm{dL}: 1 \mathrm{mg} / \mathrm{dL} \text { ), renal dysfunction or } \\
\text { diabetes }\end{array}$ \\
\hline TSH & To evaluate for thyroid dysfunction \\
\hline $\mathrm{B}_{12}$ level, Methylmalonic acid & To look for evidence of $\mathrm{B}_{12}$ deficiency \\
\hline
\end{tabular}

Secondary Laboratory Tests (Considered for

Use in Select Patients)

Function in $\mathrm{OH} / \mathrm{nOH}$ differential diagnosis

Albumin

Liver enzyme testing, albumin

Neurological antibody studies (paraneoplastic panel)

Serum and urine protein electrophoresis
To identify poor nutrition or chronic illness

To evaluate for hepatic dysfunction in patients with weight loss and constitutional symptoms

To identify autoantibodies; rarely indicated; only in patients with subacute onset of $\mathrm{nOH}$ in the presence of other neurological or constitutional symptoms suggesting an autoimmune or paraneoplastic syndrome. A pure autonomic failure syndrome should be tested for anti-ganglionic acetylcholine receptor antibodies

To identify a monoclonal gammopathy; only in patients with features of peripheral neuropath 
as patients are strongly encouraged to keep a diary of posture/activity), but also to identify supine hypertension, which is commonly seen in patients suffering autonomic dysfunction, whether or not they are experiencing $\mathrm{OH}$ [7].

\section{If the diagnosis is $\mathrm{OH}$ and not $\mathrm{nOH}$}

Non-neurogenic causes for $\mathrm{OH}$ are common and frequently include effects of medication (antihypertensive agents, antidepressants, and alpha-blockers being the most common; a comprehensive list is noted in Table 3), blood volume depletion, or chronic illness with deconditioning. It is useful to differentiate between $\mathrm{OH}$ and $\mathrm{nOH}$ because of the significantly greater morbidity and mortality associated with $\mathrm{nOH}[3,6]$. Many of the diagnosis and management points noted throughout this paper are appropriate for use in all individuals with $\mathrm{OH}$. Readers are referred to several comprehensive reviews for further information $[22,33,42]$. A full review of the diagnosis and management of non-neurogenic $\mathrm{OH}$ is outside the scope of this paper.

\section{Grading of nOH after diagnosis}

After making a diagnosis of $\mathrm{nOH}$, it is was the opinion of the panel that it is important to establish its severity. A proposed grading scale for $\mathrm{nOH}$ is based on the total drop in systolic blood pressure, duration of standing time, and the number and severity of symptoms that affect activities of daily living [29]. The proposed grading scale is presented in Table 4. The purpose of the grading scale is to help clinicians decide when to refer a patient to a specialist. For example, depending on comfort level, a patient presenting with Grade 1 or 2 may not require referral; whereas, consideration of referral for a patient presenting with Grade 3 or $4 \mathrm{nOH}$ is reasonable.

\section{Post-prandial hypotension}

It should be noted that large meals, particularly those high in carbohydrates or associated with alcohol, can magnify the drop in blood pressure. Elderly persons are more susceptible to these effects [8]. If symptoms are more

Table 3 Common medications that may cause $\mathrm{OH}$ or exacerbate the symptoms of nOH

\begin{tabular}{|c|c|}
\hline Class of medications & Common examples \\
\hline Dopaminergic agents & Levodopa, dopamine agonists \\
\hline $\begin{array}{l}\text { Antidepressants (particularly tricyclic } \\
\text { agents) }^{\mathrm{a}}\end{array}$ & Amitriptyline, nortriptyline, imipramine, desipramine \\
\hline Anticholinergics & Atropine, glycopyrrolate, hyoscyamine \\
\hline \multicolumn{2}{|l|}{ Anti-hypertensive agents } \\
\hline \multicolumn{2}{|l|}{ Preload reducers } \\
\hline Diuretics ${ }^{\mathrm{a}}$ & Furosemide, torsemide, acetazolamide, hydrochlorothiazide, spironolactone \\
\hline Nitrates $^{\mathrm{a}}$ & Nitroprusside, isosorbide dinitrate, nitroglycerin \\
\hline Phosphodiesterase E5 inhibitors & Sildenafil, vardenafil, tadalafil \\
\hline \multicolumn{2}{|l|}{ Vasodilators } \\
\hline Alpha-1 adrenergic antagonists ${ }^{\mathrm{a}}$ & Alfuzosin, doxazosin, prazosin, terazosin, tamsulosin (used primarily for benign prostatic hyperplasia) \\
\hline $\begin{array}{l}\text { Dihydropyridine calcium channel } \\
\text { blockers }\end{array}$ & Amlodipine, nifedipine, nicardipine \\
\hline Other direct vasodilators & Hydralazine, minoxidil \\
\hline \multicolumn{2}{|l|}{ Negative inotropic/chronotropic agents } \\
\hline Beta-adrenergic blockers & $\begin{array}{l}\text { Propranolol, metoprolol, atenolol, bisoprolol, nebivolol (also vasodilator), carvedilol (also alpha-1 } \\
\text { antagonist), labetalol (also alpha-1 antagonist) }\end{array}$ \\
\hline $\begin{array}{l}\text { Non-dihydropyridine calcium } \\
\text { channel blockers }\end{array}$ & Verapamil, diltiazem \\
\hline \multicolumn{2}{|l|}{ Central sympatholytic agents } \\
\hline Centrally acting alpha- 2 agonists & Clonidine \\
\hline False neurotransmitters & Alpha-methyldopa \\
\hline \multicolumn{2}{|c|}{ Renin-angiotensin system (RAS) antagonists } \\
\hline $\begin{array}{l}\text { Angiotensin converting enzyme } \\
\text { (ACE) inhibitors }\end{array}$ & Captopril, enalapril, perindopril, \\
\hline $\begin{array}{l}\text { Angiotensin receptor type II } \\
\text { blockers (ARB) }\end{array}$ & Losartan, telmisartan, candesartan \\
\hline
\end{tabular}

${ }^{a}$ Agents that may cause more significant worsening of $\mathrm{OH} / \mathrm{nOH}$ 
Table 4 Proposed grading scale for $\mathrm{nOH}$ [27]

\begin{tabular}{ll}
\hline Grade & Attributes \\
\hline 1 & Infrequent symptoms/unrestricted standing time AND mild OH [20-30 mmHg drop in SBP during supine-to-standing test] \\
2 & $\geq 5$ min standing time (but not unrestricted) AND [ $>30 \mathrm{mmHg}$ drop in SBP OR moderate impact ADL] \\
3 & $<5$ min standing time AND [ $>30 \mathrm{mmHg}$ drop in SBP OR severe impact on ADL] \\
4 & $<1$ min standing time AND [ $>30 \mathrm{mmHg}$ drop in SBP OR incapacitated]
\end{tabular}

A patient with grade 3 or $4 \mathrm{nOH}$ should be treated by a healthcare provider with experience in managing $\mathrm{nOH}$

$S B P$ systolic blood pressure, $A D L$ activities of daily living
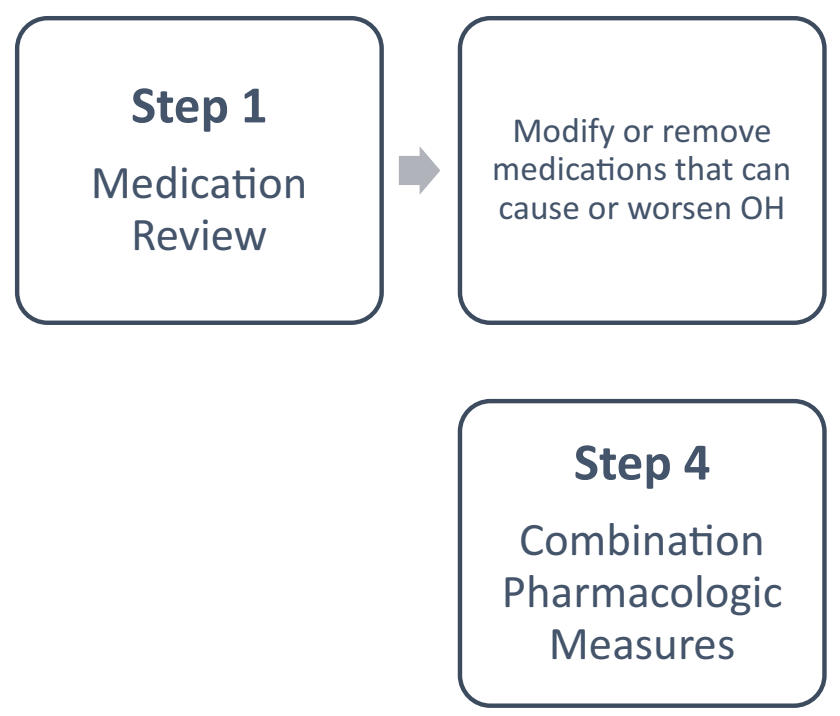

Fig. 2 A 4-step process for treating $\mathrm{nOH}$

prominent postprandially, then measurement of orthostatic blood pressures before and after meals should be considered.

\section{Treating nOH}

Once a patient is diagnosed with $\mathrm{nOH}$, the goal of treatment should not be to normalize standing blood pressure, but the principal treatment goals should serve to reduce the burden of symptoms (especially falls), prolong standing time, and improve the physical capabilities of the patient to restore independence in activities of daily living. A treatment algorithm for nOH that encompasses a 4-step hierarchical process is proposed (Fig. 2): (1) assessing and adjusting pre-existing medications, (2) utilizing non-pharmacologic approaches, (3) implementing single-agent pharmacologic treatment, and (4) with great caution, combining pharmacologic treatments. At each step, it is recommended that the patient undergo a 2-week assessment to establish whether sufficient symptomatic benefit has been achieved before moving onto successive steps. Each facet of the algorithm is described in detail below.

\section{Treating nOH一step 1: review and adjust current medications}

After establishment of a diagnosis of symptomatic nOH, it is imperative to first consider pharmacologic simplification by reducing or discontinuing medication that exacerbate $\mathrm{nOH}$. One of the keys to initial success is to complete a comprehensive medication review so that adjustments in regimens can be made as needed. Many medications (including those commonly used for treatment of PD, hypertension, or bladder symptoms) can lower blood pressure and exacerbate the symptoms of nOH (Table 3). Discontinuation or dose reduction of medications which can potentially aggravate orthostatic symptoms such as diuretics, vasodilators, and medications with negative chronotropic properties such as beta blockers may be sufficient to resolve symptoms of $\mathrm{nOH}$ in some patients.

Once a medication review has been conducted, it is recommended that any planned changes be discussed with the prescribing clinician such as: taking the patient off a particular drug, lowering current doses, or changing the dosing schedule. While there is limited published literature 
supporting this recommendation there is strong expert opinion underlying this approach. Following each adjustment to medication, changes to symptoms of nOH should be assessed, and this can be accomplished by asking the patient to respond to the screening questions listed in Table $1[7,43]$.

\section{Treating nOH—step 2: non-pharmacological measures}

The next step in the treatment algorithm is to have the patient incorporate a number of simple non-pharmacological measures into their daily routines to address symptoms due to $\mathrm{nOH}$. From a practical perspective, these measures are often incorporated into a treatment plan in parallel to the changes to pharmacology outlined in step 1 above. For patients who are experiencing syncope, near-syncope, or falls, there is some urgency to eliminating destabilizing postural changes. Hence, non-pharmacologic measures may be used individually, but are most effective when used in combination or while concomitantly titrating pharmacologic treatments.

\section{Blood volume repletion}

Patients with $\mathrm{nOH}$ require interventions which are aimed at ensuring normal or even expanded blood volume. Many patients with $\mathrm{nOH}$, especially older patients, are often blood volume depleted due to inadequate oral fluid intake [44]. This may be due to voluntary restriction of intake for self-management of common conditions causing urinary urgency and urinary frequency including benign prostatic hyperplasia (BPH), overactive bladder, neurogenic bladder, stress incontinence or similar bladder dysfunctions as are commonly seen in many neurodegenerative disorders. However, the most common identifiable and readily treatable problem is decreased daily water intake. Most patients are unaware of the volume of water intake necessary during a typical day. A minimum of $64 \mathrm{oz}$ (approximately $2 \mathrm{~L}$ ) of water daily is recommended to achieve adequate daily hydration, although many clinicians recommend over $100 \mathrm{oz}$ ( $3 \mathrm{~L}$ ) daily to ensure blood volume repletion, depending on cardiac status. Modifications in fluid volume recommendations also need to be considered in geographic areas with warmer weather or during the summer season.

In addition to maintaining intravascular blood volume and to support standing blood pressure, patients with $\mathrm{nOH}$ who rapidly consume (within $5 \mathrm{~min}$ ) $16 \mathrm{oz}$ (approximately $500 \mathrm{ml}$ ) of free water can raise systolic blood pressure by $30 \mathrm{mmHg}$ within $5 \mathrm{~min}$ [45]. The effect is due to a hypoosmolar reflex in the portal circulation and can last for an hour to help alleviate the symptoms of $\mathrm{nOH}$ experienced on standing [46, 47]. Liquids other than water do not provide the same blood pressure response [48, 49]. Thus, proper hydration can produce both acute and long-lasting significant clinical benefits to patients with $\mathrm{nOH}$ [46, 50-53].

\section{Salt intake}

Another non-pharmacologic treatment is to monitor and adjust as needed the amount of salt that the patient is ingesting. Because salt is typically seen as a negative dietary component, patients may try to remove or at least reduce salt from their diet. However, many patients who suffer orthostatic symptoms have an inadequate intake of salt. This can be verified by checking the 24-h urinary sodium (in patients who are not taking diuretics or fludrocortisone, urinary sodium $>100 \mathrm{mEq} / 24 \mathrm{~h}$ indicates salt repletion). For the patient with $\mathrm{nOH}$, it is recommended that they add up to 1-2 teaspoons (2.3-4.6 g) of salt per day to their normal diet [54-56]. Patients at risk for heart failure or severe peripheral edema must be closely monitored for worsening symptoms and salt intake adjusted downward accordingly [43, 57]. The long-term risks associated with greater salt intake (e.g., increased intravascular volume, worsening edema, worsening heart failure, increased blood pressure) need to be weighed against the short-term risks of nOH resulting in fall injury and the negative impact on activities of daily living. The long-term risks of high sodium diets in individuals with orthostatic hypotension have not been well studied.

\section{Physical conditioning}

Lower body strength training and moderate, non-strenuous activities may be incorporated into standard treatment for patients with nOH $[58,59]$. Deconditioning occurs very quickly in bed bound or hospitalized patients and will exacerbate the magnitude of the blood pressure drop in patients with $\mathrm{nOH}$. We advocate the use of exercise that is not gravitationally challenging, such as a stationary recumbent bicycle, rowing machine, or water-based activities. Upright exercise, such as treadmill walking or running, should be avoided in some patients because of the risk of falls due to nOH. Patients should be cautioned that strenuous activity may temporarily exacerbate symptoms of $\mathrm{nOH}$ due to increased core body temperature and peripheral vasodilation as described below. To help mitigate against this occurring, patients should be well hydrated prior to exercise and should be careful when standing after an exercise session.

\section{Avoid increased core body temperature}

Elevation in body temperature causes peripheral vasodilation. Patients with nOH should avoid situations that could 
increase core body temperature, such as excessive highintensity exercise, exercise when ambient temperature and humidity are high, utilization of hot tubs, spas, or saunas, prolonged hot showers, etc. [60]. Simple safety adjustments, such as using a shower chair, will help prevent complications. Additionally, individuals with autonomic failure may have impaired thermoregulatory capacity and may be at increased risk for hyperthermia. An example of impaired thermoregulation in autonomic failure is shown by the lack of the expected nocturnal decrease of body core temperature that has been described in patients with MSA [61].

\section{Head-up position while sleeping}

Elevating the head of the bed (through use of a wedge under the mattress, or placing blocks under the legs of the bed's headboard so that the head is 6-9 inches $(15-23 \mathrm{~cm})$ higher than the feet-stacked pillows are not adequate) will reduce supine hypertension [62]. Supine hypertension commonly leads to a pressure diuresis that occurs resulting in nocturia and blood volume depletion overnight. This nocturnal forced diuresis can be decreased by elevating the head of the bed. In addition, the modest effects of gravity in the head-up position will maintain activation of the renin-angiotensin-aldosterone system and maintain higher blood pressure in the morning. The net result is a diminished magnitude of blood pressure drop in the morning [63].

\section{Compression garments}

Compression garments are another mechanism to combat blood pressure changes due to postural venous pooling [64, 65]. Compression of $30-40 \mathrm{mmHg}$ is required to improve venous return and provide a meaningful blood pressure impact. Because most of the pooling occurs in the splanchnic-mesenteric bed, waist-high compression garments are the most effective, followed by thigh-high compression stockings. Knee-high stockings are not effective, although they are widely used for treatment of orthostatic hypotension and many patients are convinced of their effectiveness. Unfortunately, compliance with the use of compression stockings is low because they require fitting, are difficult to put on, and uncomfortable in hot climates. Abdominal binders offer an effective alternative [66], and arguably should be tried first, alone or if necessary in combination with leg compression. It was recently shown that an automated inflatable abdominal binder that supplied $40 \mathrm{mmHg}$ in compression was as effective as midodrine in managing $\mathrm{OH}$ in patients with autonomic failure [67].

\section{Diet}

In patients with $\mathrm{OH} / \mathrm{nOH}$, normal sympathetic activity cannot compensate for blood pooling within the splanchnic circulation after eating. With nOH, sympathetic vasoconstrictor nerve activity is deficient and many patients become severely hypotensive within $2 \mathrm{~h}$ of eating $[8,68]$. It is important to recognize this problem because treatment of $\mathrm{OH} / \mathrm{nOH}$ can diminish symptoms post-meal. Patients can be asked to measure their blood pressure before and 30 min after a high carbohydrate meal. In individuals with postprandial hypotension, smaller, more frequent meals are recommended $[69,70]$. There is also some evidence that a low glycemic diet may have a beneficial effect on the symptoms of $\mathrm{OH} / \mathrm{nOH}[68,71,72]$. Finally, postprandial hypotension can be reduced with caffeine [73] or acarbose [74].

\section{Anemia and vitamin/mineral deficiencies in the diet}

Anemia leads to decreased blood viscosity and oxygen carrying capacity and may worsen symptoms of $\mathrm{OH} / \mathrm{nOH}$ [75]. Vitamin B12 deficiency $(<250 \mathrm{pg} / \mathrm{mL}$ with elevated methylmalonic acid levels) may be also be associated with postural instability and can cause $\mathrm{OH}[76,77]$. B12 deficiency and anemia should be corrected and ongoing observation is necessary to prevent recurrence. Thus, changes in diet as well as vitamin and iron supplementation may be helpful for some patients with $\mathrm{nOH}$.

\section{Treating nOH—step 3: initial pharmacologic treatment}

If the implementation of non-pharmacologic measures does not adequately improve the symptoms of $\mathrm{nOH}$, then it becomes necessary to initiate pharmacotherapy. For patients who are experiencing syncope, near-syncope, or falls, the potential consequences are so grave that some clinicians believe that institution of pharmacotherapy at the outset of management is appropriate. Clinicians must individualize treatment based upon the urgency of the symptoms.

Until 2014, the two drugs primarily used to treat $\mathrm{nOH}$ were fludrocortisone and midodrine (of which only midodrine has received FDA approval for treatment of $\mathrm{OH}$ ). In 2014, droxidopa received FDA approval for the treatment of nOH. The selection of one drug over the other, in many situations, was related to clinician preference and experience. Below, we present an overview of the key drugs used to treat $\mathrm{nOH}$ and the recommendations for usage. One of the challenges associated with treating $\mathrm{nOH}$ pharmacologically is the limited availability of clinical evidence and lack of comparative effectiveness studies. 


\section{FDA-approved drugs for the treatment of $\mathrm{OH} / \mathrm{nOH}$}

\section{Midodrine}

Midodrine is a prodrug whose metabolite, desglymidodrine, is an $\alpha 1$-adrenoreceptor agonist that increases vascular resistance and blood pressure. Typical dosing is between 2.5 and $15 \mathrm{mg}$ once to three times daily during waking hours (an example schedule of three times daily would be dosing prior to getting out of bed, before lunch, and mid-afternoon) [7]. The dose is typically up-titrated to symptomatic relief. In multiple clinical trials, midodrine resulted in a significant increase in systolic and diastolic blood pressure, as well as modest improvements in orthostatic symptoms [11-13]. Midodrine carries a risk of significant supine hypertension; so it is recommended that individuals not take midodrine within 5 h of bedtime [11-13]. A high supine blood pressure seen shortly after midodrine administration should not cause the drug dose to be decreased or stopped, but managed by avoiding the supine posture. A meta-analysis of seven trials with midodrine (325 total subjects) found an increased incidence of supine hypertension and that the pooled risk ratio was 6.38; however, it is worth re-stressing that patients treated with midodrine should not rest or sleep in the supine position; rather, recumbency should always be assumed in the head-up position [78]. Other side effects with midodrine include piloerection, scalp itching, and urinary retention [79]. Caution should also be exercised in patients with congestive heart failure and chronic renal failure [79].

\section{Droxidopa}

Droxidopa is an orally administered norepinephrine pro-drug that is converted into norepinephrine both in the central nervous system and in peripheral tissues, including sympathetic peripheral nerve endings. Increases in circulating plasma norepinephrine levels peak at $6 \mathrm{~h}$ following treatment with droxidopa and levels of norepinephrine remain elevated for at least $46 \mathrm{~h}$ [80]. Replenishment of neural norepinephrine is believed to be the primary mechanism of action for improvement of standing blood pressure with droxidopa. Droxidopa can be dosed from 100 to $600 \mathrm{mg}$ three times daily during waking hours. A recommended dosing schedule would be at $8 \mathrm{AM}$, noon, and 4 PM. In the clinical trials, droxidopa was titrated every $48 \mathrm{~h}$ to either symptomatic benefit and/or intolerable adverse events. Clinically, droxidopa has been evaluated in Phase 3 studies and has demonstrated significant improvement in the symptoms of $\mathrm{nOH}$ such as dizziness, lightheadedness, weakness, fatigue, and in improvements to activities of daily living [15-17]. Additionally, in studies of droxidopa for the treatment of $\mathrm{nOH}$, the rate of falls and fallrelated adverse events demonstrated a favorable trend (but not statistically significant) in the groups of patients receiving droxidopa versus those receiving placebo [15-17]. A post hoc analysis of the most recent study of droxidopa for the treatment of $\mathrm{nOH}$ showed that the group treated with droxidopa had $68 \%$ fewer falls than the placebo group (229 vs. 716) [17]. Droxidopa, like other agents to treat $\mathrm{nOH}$, is not recommended to be taken within $5 \mathrm{~h}$ of bedtime to avoid the risk of supine hypertension. Side effects observed with droxidopa included headache, dizziness, nausea, fatigue, and supine hypertension [15-17]. Caution should be exercised in patients with congestive heart failure and chronic renal failure.

\section{Off-label use of FDA-approved drugs for the treatment of orthostatic hypotension}

\section{Fludrocortisone}

Fludrocortisone has been used off-label for many years for the treatment of $\mathrm{OH} / \mathrm{nOH}$, and even though the level of data supporting the use of fludrocortisone in $\mathrm{OH} / \mathrm{nOH}$ is low, it is included in treatment guidelines based on expert opinion [22]. It acts by increasing renal sodium and water reabsorption, thus expanding intravascular blood volume. Fludrocortisone's long-term efficacy, however, may be related to increased vascular resistance. Fludrocortisone is typically dosed at $0.1-0.2 \mathrm{mg} /$ day with little benefit being observed with increasing the dose beyond $0.3 \mathrm{mg} /$ day (and an associated increase in risks of side effects, including hypothalamic-pituitary-adrenal axis suppression) [81-84]. The onset of action occurs over 3-7 days. The main side effects of fludrocortisone include supine hypertension, hypokalemia, and edema. It should be used with caution in patients with congestive heart failure [22].

\section{Pyridostigmine}

Pyridostigmine is an acetylcholinesterase inhibitor that has been used off-label for the treatment of $\mathrm{OH} / \mathrm{nOH}$ because it potentiates neurotransmission at peripheral cholinergic synapses including those in the sympathetic ganglia. Pyridostigmine is thought to work in $\mathrm{OH}$ by amplifying the increased sympathetic nerve activity in response to orthostatic stress. Therefore, it is likely more useful in less severe patients with residual sympathetic function, and has the advantage of not worsening supine hypertension. Typical dosing is $30-60 \mathrm{mg}$ once to three times per day. Several small studies have reported a modest improvement in $\mathrm{OH}$ and orthostatic symptoms [14, 18-21]. Patients may experience adverse side effects associated with cholinergic stimulation, including abdominal cramps, diarrhea, sialorrhea, excessive sweating, and urinary incontinence. Many patients with $\mathrm{nOH}$ also have autonomic failure resulting in constipation and anhidrosis, so these side effects may be salutary for some patients. 


\section{Recommendations for initiating $\mathrm{nOH}$ treatment}

There have been no head-to-head comparison studies to guide the initial choice of $\mathrm{nOH}$ treatments. An individualized treatment regimen should consider severity, comorbid disease (especially cardiac or renal failure), and treatment goals. Midodrine has an FDA-approved indication for the treatment of symptomatic OH; FDA approval was based on studies showing an improvement in upright blood pressure as a surrogate for symptom relief. In contrast, the FDA-approved droxidopa with an orphan designation for the treatment of $\mathrm{nOH}$ based on studies showing improvement in symptoms of $\mathrm{nOH}$. Patients receiving droxidopa reported a decrease in dizziness, lightheadedness, feeling faint, or feeling as if they might black out compared with those receiving placebo. There have been no long-term studies on the durability of the treatment effect for either midodrine or droxidopa. However, a longterm study is underway to study durability of effectiveness with droxidopa (NCT02586623) in patients with $\mathrm{nOH}$ for up to 36 weeks of treatment.

\section{Recommendations for changing $\mathrm{nOH}$ treatment}

Once initial therapy has begun, symptomatic benefit, including impact on activities of daily living, and changes in blood pressure need to be assessed frequently. If symptoms do not improve after reaching maximum labeled dose, it is recommended that the treatment be changed and symptomatic benefit be assessed once more. This process is iterative until either symptomatic benefit is achieved or maximum tolerable dose of the therapy is reached.

\section{Treating nOH-step 4: combination pharmacotherapy}

Little data exists to determine efficacy and safety of different combinations of therapy compared to monotherapy for $\mathrm{nOH}$. Based on the experience of the consensus panel, the recommendation is to appropriately titrate to maximum tolerable dose of a single agent and then, if symptomatic benefit is not obtained, consider switching to a different therapy or adding a second agent and titrate from its lowest starting dose.

\section{Assessing nOH treatment success}

Assessment of treatment success needs to be a multifaceted approach involving predominantly the measurement of symptomatic improvements as well as ongoing blood pressure measurements. It is critical that patients are educated on the various symptoms and about how to keep a diary of symptoms. Similarly, it is necessary for the patient to conduct a period of home monitoring of blood pressure after implementing new or additional non-pharmacologic measures or after a change in treatment or dose. We recommend that patients check their blood pressures at home in the supine head-up position (at bedtime, prior to arising in the morning, and while the patient is in their normal head-up sleeping position). Patients taking pressor medications such as midodrine or droxidopa should avoid the supine position during the $4-5 \mathrm{~h}$ after taking medication), and check blood pressure after $3 \mathrm{~min}$ of standing. We recommend checking blood pressures first thing in the morning prior to taking any morning medications, when symptomatic, and at bedtime for several days. The blood pressure diary should be evaluated by the healthcare provider 2 weeks after any therapeutic change to determine the need for further adjustments. (An example patient diary for blood pressure and heart rate monitoring is provided in Appendix I). If blood pressure measurements have been stable, a reduction in monitoring frequency can be considered, but reinstituted if symptoms worsen or if medications are changed. Lastly, 24-h ambulatory blood pressure monitoring can be considered so that there is an ongoing record of the impact of treatment on blood pressure. Additional clinical assessments will be largely driven by symptom frequency and severity. However, re-assessment of the clinical condition should occur at every visit via symptom review and orthostatic blood pressure measurements.

\section{Referring the nOH patient}

With appropriate education, the screening, diagnosis, and treatment of $\mathrm{nOH}$ are well within the purview of both primary and specialist clinicians. With a diagnosis of nOH, the clinician can assign an $\mathrm{OH}$ severity Grade based on blood pressure changes, symptoms, and impact on activities of daily living. Once diagnosis is established, the clinician can take the patient through steps 1,2 , and 3 of the treatment algorithm. However, if the patient experiences pharmacotherapy failure, it may be useful to refer the patient to a specialist who is experienced in treating patients with $\mathrm{nOH}$. Additionally, if the clinician is at any time uncomfortable with treating a patient with $\mathrm{nOH}$ of high severity (Grades 3 to 4), they should refer the patient to a specialist with expertise in the treatment of $\mathrm{nOH}$.

\section{Supine hypertension}

\section{Defining supine hypertension in patients with $\mathbf{n O H}$}

According to the Eighth Joint National Committee (JNC8) hypertension guidelines, essential hypertension is a blood pressure consistently $\geq 140 / 90 \mathrm{mmHg}$ [85]. Supine 
hypertension in $\mathrm{nOH}$ patients is arbitrarily defined as a systolic blood pressure $\geq 150 \mathrm{mmHg}$ or diastolic blood pressure $\geq 90 \mathrm{mmHg}$ while in the supine position. General treatment guidelines recommend intervention for hypertension, but supine hypertension associated with $\mathrm{nOH}$ requires additional considerations. In patients with autonomic failure causing $\mathrm{nOH}$, supine hypertension is common and part of the underlying disease process since these patients lack the normal blood pressure buffering mechanisms that offset hypertension. In addition, frequent periods of $\mathrm{OH}$ may lead to chronic activation of the renin-angiotensin system.

A supine systolic blood pressure of up to $160 \mathrm{mmHg}$ should be monitored but does not generally warrant treatment, especially if the symptoms of $\mathrm{nOH}$ have improved. The long-term risks associated with supine hypertension need to be balanced with the short-term risks of OH. Expert recommendations for the management of supine hypertension in the setting of nOH suggest that supine hypertension requires intervention if systolic blood pressure exceeds the range of $160-180 \mathrm{mmHg}$. However, it should be noted that individuals with the largest drops in blood pressure upon standing ( $>80 \mathrm{mmHg}$ drop) will require significantly higher supine blood pressures in order to achieve a standing position, and therefore permissive supine hypertension may need to be tolerated.

\section{Measuring supine hypertension in patients with $\mathrm{nOH}$}

The first step in evaluating supine hypertension in the patient with $\mathrm{nOH}$ is obtaining a series of blood pressure measurements. Home supine and standing blood pressures should be obtained. The supine assessment should be in the morning (before arising) and at bedtime with the patient in their normal sleeping position and with the head of the bed raised. If necessary, 24-h blood pressure monitoring may be warranted in some patients. Blood pressure should be monitored for a week or more to establish a pattern of typical blood pressure. Once a baseline has been established and treatment initiated for $\mathrm{nOH}$, regular blood pressure monitoring for a period of 2 weeks following treatment initiation is crucial to gauge the impact of treatment on supine hypertension.

\section{Supine hypertension associated with $\mathrm{nOH}$}

It is critical for clinicians to understand the physiology underlying both $\mathrm{nOH}$ and supine hypertension and the associated risks of each when they manage patients with nOH. Neurogenic $\mathrm{OH}$ is associated with loss of baroreflex function that normally buffers changes in blood pressure in both directions. Therefore, patients with autonomic nervous system dysfunction typically have $\mathrm{nOH}$ and supine hypertension. In addition to supine hypertension being common in patients with $\mathrm{nOH}$, many of the medications used to treat $\mathrm{nOH}$ can cause or exacerbate supine hypertension. Because $\mathrm{OH} / \mathrm{nOH}$ and supine hypertension are hemodynamic opposites, improving one can worsen the other. Thus, all patients with $\mathrm{nOH}$ should be evaluated for supine hypertension. There are differences in clinical practice among clinicians who treat $\mathrm{nOH}$. Some clinicians may not treat $\mathrm{nOH}$ for fear of exacerbating supine hypertension, while others may aggressively treat $\mathrm{nOH}$ while accepting the resulting supine hypertension. Unlike the potential longterm consequences of hypertension in non-PD patients, the risks of $\mathrm{nOH}$ are immediate and represent potential major health threats. By extrapolation, similar recommendations can be made in multiple system atrophy $[3,4]$. In contrast, the data is less clear in individuals with pure autonomic failure.

In most patients with $\mathrm{nOH}$, there are strong reasons for prioritizing the treatment of $\mathrm{nOH}$ over supine hypertension $[10,86]$. Symptomatic nOH carries a variety of debilitating symptoms including postural related dizziness, syncope, fatigue, weakness, and vision impairment. All of these symptoms can contribute to an increase in the occurrence of falls, which is one of the most common reasons for hospital admission for PD patients. Falls due to nOH can lead to numerous complications that can result in death. However, there is no agreement among clinicians, when, or how vigorously supine hypertension should be treated with nOH and there is no clinical study evidence to base guidelines. At the very minimum, all patients with $\mathrm{nOH}$ and supine hypertension should be advised to avoid supine posture during the day and elevate the head of the bed as tolerated during the night. Clinicians should manage patients with significant supine hypertension with shortacting antihypertensive agents given at bedtime and avoid fludrocortisone. Since patients with MSA have a short life expectancy and experience rapid deterioration of motor abilities, enhancement of quality of life should take precedent and $\mathrm{nOH}$ should be aggressively treated to allow for improved mobility in these patients. However, once an MSA patient becomes wheelchair bound there may be less urgency to treating $\mathrm{nOH}$. In patients with PD and PAF the decision to prioritize the treatment of $\mathrm{nOH}$ over supine hypertension should be individualized. If supine hypertension can be treated without worsening $\mathrm{nOH}$, the clinician should consider using short-acting agents at night. Lastly, those few patients who have episodes of seated hypertension during the day should be referred to specialized centers.

As stated above, if patients with $\mathrm{nOH}$ are experiencing supine hypertension (systolic blood pressure of 
Table 5 Proposed treatments for supine hypertension related to $\mathrm{nOH}$

\begin{tabular}{lll}
\hline Treatment options* & Mechanism of action & Typical dose \\
\hline Captopril $^{*}$ & ACE inhibitor & $25 \mathrm{mg} \mathrm{qhs}$ \\
Clonidine $^{\mathrm{a}}$ & Central $\alpha-2$ agonist & $0.2 \mathrm{mg}$ with evening meal \\
Hydralazine & Peripheral smooth muscle relaxant & $10-25 \mathrm{mg}$ qhs \\
Losartan & Angiotensin II receptor antagonist & $50 \mathrm{mg}$ qhs \\
Nitroglycerine patch & Vasodilator & $0.1 \mathrm{mg} / \mathrm{h}$ patch qhs (remove patch in AM)
\end{tabular}

*Short-acting antihypertensive medications for treatment of supine hypertension should only be administered at bedtime, not during daytime hours. Many medications have BID or TID as the recommended dosing regimen, and patients may inadvertently start taking these medications during daytime hours and worsen symptoms of $\mathrm{nOH}$

a Use of clonidine carries a risk of a morning 'hangover' effect
$160-180 \mathrm{mmHg}$ or diastolic blood pressure of $90-100 \mathrm{mmHg}$ ), the decision to treat should be individualized. However, if patients with $\mathrm{nOH}$ are experiencing severe supine hypertension (systolic blood pressure of $>180 \mathrm{mmHg}$ or diastolic blood pressure of $>110 \mathrm{mmHg}$ ), they could be treated in the evening using short-acting antihypertensive agents (Table 5). Individuals with the most severe supine hypertension often have the most severe $\mathrm{nOH}$ and therefore these patients should be educated in the risks of worsening $\mathrm{nOH}$ with treatment. In particular, nocturnal visits to the bathroom may become dangerous if supine hypertension is treated too aggressively. It is also important for these patients to avoid the use of diuretics and longacting antihypertensive agents because the blood volume depletion attendant to diuretics and hypotensive effects of long-acting antihypertensive may markedly worsen $\mathrm{nOH}$, even though they might have been intended to mitigate supine hypertension. Additionally, patients with $\mathrm{nOH}$ must avoid the supine posture during the day. A head-up reclining posture is recommended for repose.

\section{Limitations}

There are a number of limitations to the current publication. The recommendations listed in this document are based on expert opinion, but do not contain sufficient evidence to support official guidelines. However, the recommendations were included with the goal of providing practical information to the many physicians without specific training or experience in autonomic disorders that are most likely to manage patients with orthostatic hypotension. Additional studies are necessary to determine the utility of these recommendations.

\section{Conclusions}

To date, little published literature is available on a "standardized approach" to the screening, diagnosis, and treatment of patients with $\mathrm{OH} / \mathrm{nOH}$ and associated supine hypertension. As such, the recommendations of this panel, which were based on the discussions and experiences of the panel along with evidence in the literature, should provide clinicians with a useful working approach to dealing with this complex condition. The panel recommended that additional study in screening, diagnosis, and treatment of patients with $\mathrm{OH} / \mathrm{nOH}$ and associated supine hypertension is necessary. In particular, additional studies of the treatment of nOH should be conducted to refine the diagnosis and treatment algorithms and to provide definitive evidence of efficacy and safety of medications that are currently used, but not approved, for the treatment of patients with $\mathrm{nOH}$.

Acknowledgements The authors were participants in a consensus panel meeting which took place in Boston, MA, USA, on November 7, 2015. This meeting was jointly held by the American Autonomic Society and the National Parkinson Foundation and funded by Lundbeck. All authors have contributed to the development and writing of the manuscript. In addition, medical writing and editorial assistance was provided by Keith C. Lantz, MS, CMPP (Link Health Group, LLC, Bridgewater, NJ) and funded by Lundbeck.

\section{Compliance with ethical standards}

Conflicts of interest Dr. Gibbons is on advisory boards for Pfizer and Lundbeck, is on data safety monitoring boards for Janssen and Astellas, and received research funding from Celgene and Grifols Inc. Dr. Schmidt has nothing to disclose. Dr. Biaggioni served as a clinical trial investigator for Lundbeck and is a consultant/advisor for Shire Pharmaceutical and Lundbeck. Dr. Frazier-Mills is on an advisory board for Lundbeck. Dr. Freeman is on an advisory board for Lundbeck. Dr. Isaacson has received honoraria for CME, is a consultant/advisor, received research funding/grants, and/or is a promotional speaker on behalf of AbbVie, Acadia Pharmaceuticals, Adamas Pharmaceuticals, Addex Therapeutics, Allergan, Allon Therapeutics, Amarantus Bioscience, AstraZeneca, Auspex Pharmaceuticals, Biotie Therapies, Britannia Pharmaceuticals, Chelsea Therapeutics, Civitas Therapeutics, Cynapsus Therapeutics, Eisai, GE Healthcare, GSK, Impax Pharmaceuticals, Ipsen, Kyowa, Lilly, Lundbeck, Merck, Schering-Plough, Medtronics, Merz, Michael J Fox Foundation, Novartis, Neurocrine Biosciences, NIH, Novartis, Orion, Parkinson Study Group, Pfizer, Phytopharm Plc, Purdue Pharma, Roche, Santhera Pharmaceuticals, Serono, Shire, Teva, UCB, US World Meds, Vanda Pharmaceuticals, and Xenoport. Dr. Karabin is a speaker and consultant for Lundbeck. Dr. Kuritzky is a 
speaker, consultant, and on an advisory board for Lundbeck. Dr. Lew is a consultant/advisor for Teva, US World Meds, UCB, Acadia, Auspex, Lundbeck, Abbvie, Impax, Cynapsus, Adamas, and Jazz; he is a speaker for Teva, USWM, UCB Pharma, Lundbeck, Acadia, and Impax; and he is a clinical researcher for Parkinson's Study Group, Michael J. Fox Foundation, Civitas, Biotie, Intec Pharma, Neuroderm, the United States National Institutes of Health (NIH), and Enterin. Dr. Low has nothing to disclose. Dr. Mehdirad is a speaker for Lundbeck. Dr. Raj is on an advisory board for Lundbeck, is a consultant for GE Healthcare, is a clinical trial investigator for Medtronic and Bristol Myers Squibb, and received research funding from the Canadian Institutes of Health Research (CIHR). Dr. Vernino is on an advisory board and speaker bureau for Lundbeck and is a scientific consultant for Athena Diagnostics (a division of Quest). Dr. Kaufmann is on an advisory board for Lundbeck, ICE for Astra Zeneca, and has received research funding from the United States Food and Drug Administration (FDA) and NIH.

Open Access This article is distributed under the terms of the Creative Commons Attribution 4.0 International License (http://crea tivecommons.org/licenses/by/4.0/), which permits unrestricted use, distribution, and reproduction in any medium, provided you give appropriate credit to the original author(s) and the source, provide a link to the Creative Commons license, and indicate if changes were made.

\section{References}

1. Low PA (2008) Prevalence of orthostatic hypotension. Clin Auton Res Off J Clin Auton Res Soc 18(Suppl 1):8-13. doi:10. 1007/s10286-007-1001-3

2. Metzler M, Duerr S, Granata R, Krismer F, Robertson D, Wenning GK (2013) Neurogenic orthostatic hypotension: pathophysiology, evaluation, and management. J Neurol 260(9):2212-2219. doi:10.1007/s00415-012-6736-7

3. Maule S, Milazzo V, Maule MM, Di Stefano C, Milan A, Veglio F (2012) Mortality and prognosis in patients with neurogenic orthostatic hypotension. Funct Neurol 27(2):101-106

4. Gibbons CH, Freeman R (2015) Clinical implications of delayed orthostatic hypotension: A 10-year follow-up study. Neurology 85(16):1362-1367. doi:10.1212/WNL.0000000000002030

5. Xin W, Lin Z, Mi S (2014) Orthostatic hypotension and mortality risk: a meta-analysis of cohort studies. Heart (British Cardiac Society) 100(5):406-413. doi:10.1136/heartjnl-2013-304121

6. Freeman R (2008) Clinical practice. Neurogenic orthostatic hypotension. N Engl J Med 358(6):615-624

7. Low PA, Singer W (2008) Management of neurogenic orthostatic hypotension: an update. Lancet Neurol 7(5):451-458

8. Freeman R, Wieling W, Axelrod FB, Benditt DG, Benarroch E, Biaggioni I, Cheshire WP, Chelimsky T, Cortelli P, Gibbons CH, Goldstein DS, Hainsworth R, Hilz MJ, Jacob G, Kaufmann H, Jordan J, Lipsitz LA, Levine BD, Low PA, Mathias C, Raj SR, Robertson D, Sandroni P, Schatz IJ, Schondorf R, Stewart JM, van Dijk JG (2011) Consensus statement on the definition of orthostatic hypotension, neurally mediated syncope and the postural tachycardia syndrome. Auton Neurosci 161(1-2):46-48. doi:10.1016/j.autneu.2011.02.004

9. Loavenbruck A, Sandroni P (2015) Neurogenic orthostatic hypotension: roles of norepinephrine deficiency in its causes, its treatment, and future research directions. Curr Med Res Opin 31(11):2095-2104. doi:10.1185/03007995.2015.1087988
10. Goldstein DS, Pechnik S, Holmes C, Eldadah B, Sharabi Y (2003) Association between supine hypertension and orthostatic hypotension in autonomic failure. Hypertension 42(2):136-142

11. Jankovic J, Gilden JL, Hiner BC, Kaufmann H, Brown DC, Coghlan CH, Rubin M, Fouad-Tarazi FM (1993) Neurogenic orthostatic hypotension: a double-blind, placebo- controlled study with midodrine. Am J Med 95(1):38-48

12. Low PA, Gilden JL, Freeman R, Sheng KN, McElligott MA (1997) Efficacy of midodrine vs placebo in neurogenic orthostatic hypotension. A randomized, doubleblind multicenter study. Midodrine Study Group. JAMA 277(13):1046-1051

13. Wright RA, Kaufmann HC, Perera R, Opfer-Gehrking TL, McElligott MA, Sheng KN, Low PA (1998) A double-blind, dose-response study of midodrine in neurogenic orthostatic hypotension. Neurology 51(1):120-124

14. Singer W, Sandroni P, Opfer-Gehrking TL, Suarez GA, Klein CM, Hines S, O’Brien PC, Slezak J, Low PA (2006) Pyridostigmine treatment trial in neurogenic orthostatic hypotension. Arch Neurol 63(4):513-518

15. Kaufmann H, Freeman R, Biaggioni I, Low P, Pedder S, Hewitt LA, Mauney J, Feirtag M, Mathias CJ, Investigators NOH (2014) Droxidopa for neurogenic orthostatic hypotension: a randomized, placebo-controlled, phase 3 trial. Neurology 83(4):328-335. doi:10.1212/WNL.0000000000000615

16. Biaggioni I, Freeman R, Mathias CJ, Low P, Hewitt LA, Kaufmann H, Droxidopa I (2015) Randomized withdrawal study of patients with symptomatic neurogenic orthostatic hypotension responsive to droxidopa. Hypertension 65(1):101-107. doi:10. 1161/HYPERTENSIONAHA.114.04035

17. Hauser RA, Isaacson S, Lisk JP, Hewitt LA, Rowse G (2015) Droxidopa for the short-term treatment of symptomatic neurogenic orthostatic hypotension in Parkinson's disease (nOH306B). Mov Disord 30(5):646-654. doi:10.1002/mds.26086

18. Singer W, Opfer-Gehrking TL, McPhee BR, Hilz MJ, Bharucha AE, Low PA (2003) Acetylcholinesterase inhibition: a novel approach in the treatment of neurogenic orthostatic hypotension. J Neurol Neurosurg Psychiatry 74(9):1294-1298

19. Senard JM (2005) Pyridostigmine in the treatment of orthostatic hypotension. Clin Auton Res Off J Clin Auton Res Soc 15(6):421-422

20. Singer W, Opfer-Gehrking TL, Nickander KK, Hines SM, Low PA (2006) Acetylcholinesterase inhibition in patients with orthostatic intolerance. J Clin Neurophysiol 23(5):476-481

21. Provitera V, Nolano M, Pagano A (2006) Acetylcholinesterase inhibition and orthostatic hypotension. Clin Auton Res Off J Clin Auton Res Soc 16(2):136. doi:10.1007/s10286-006-0336-5

22. Lahrmann H, Cortelli P, Hilz M, Mathias C, Struhal W, Tassinari M (2011) Orthostatic hypotension. In: Barnes MP, Brainin M, Gilhus NE (eds) European handbook of neurological management Vol. 1, 2nd edn. Wiley-Blackwell, Oxford, pp 469-475

23. Bleasdale-Barr KM, Mathias CJ (1998) Neck and other muscle pains in autonomic failure: their association with orthostatic hypotension. J R Soc Med 91(7):355-359

24. Gibbons CH, Freeman R (2005) Orthostatic dyspnea: a neglected symptom of orthostatic hypotension. Clin Auton Res Off J Clin Auton Res Soc 15(1):40-44. doi:10.1007/s10286-005-0227-1

25. Robertson D, Kincaid DW, Haile V, Robertson RM (1994) The head and neck discomfort of autonomic failure: an unrecognized aetiology of headache. Clin Auton Res Off J Clin Auton Res Soc 4(3):99-103

26. Guaraldi P, Poda R, Calandra-Buonaura G, Solieri L, Sambati L, Gallassi R, Cortelli P (2014) Cognitive function in peripheral autonomic disorders. PLoS One 9(1):e85020. doi:10.1371/jour nal.pone. 0085020

27. Centi J, Freeman R, Gibbons CH, Neargarder S, Canova AO, Cronin-Golomb A (2016) Effects of orthostatic hypotension on 
cognition in Parkinson disease. Neurology. doi:10.1212/wnl. 0000000000003452

28. Shibao C, Grijalva CG, Raj SR, Biaggioni I, Griffin MR (2007) Orthostatic hypotension-related hospitalizations in the United States. Am J Med 120(11):975-980. doi:10.1016/j.amjmed.2007. 05.009

29. Low PA (2015) Neurogenic orthostatic hypotension: pathophysiology and diagnosis. Am J Manag Care 21(13 Suppl):s248-s257

30. Davidson C, Smith D, Morgan DB (1976) Diurnal pattern of water and electrolyte excretion and body weight in idiopathic orthostatic hypotension. The effect of three treatments. Am J Med 61:709-715

31. Ikeda T, Matsubara T, Sato Y, Sakamoto N (1993) Circadian blood pressure variation in diabetic patients with autonomic neuropathy [see comments]. J Hypertens 11(5):581-587

32. Mann S, Bellamy GR, Hunyor SN, Raftery EB, Ingall T, Bannister R (1984) Supine hypertension, blood pressure variability and circadian rhythm in autonomic failure: the role of ambulatory intraarterial monitoring. Clin Exp Pharmacol Physiol 11:347-350

33. Shibao C, Lipsitz LA, Biaggioni I, American Society of Hypertension Writing Group (2013) Evaluation and treatment of orthostatic hypotension. J Am Soc Hypertens 7(4):317-324. doi:10.1016/j.jash.2013.04.006

34. Gibbons CH, Freeman R (2006) Delayed orthostatic hypotension: a frequent cause of orthostatic intolerance. Neurology 67(1):28-32. doi:10.1212/01.wnl.0000223828.28215.0b

35. Biaggioni I (2015) Treatment: special conditions: orthostatic hypotension. J Am Soc Hypertens 9(1):67-69. doi:10.1016/j.jash. 2014.12.005

36. White NJ (1980) Heart-rate changes on standing in elderly patients with orthostatic hypotension. Clin Sci 58(5):411-413

37. Poon IO, Braun U (2005) High prevalence of orthostatic hypotension and its correlation with potentially causative medications among elderly veterans. J Clin Pharm Ther 30(2):173-178. doi:10.1111/j.1365-2710.2005.00629.x

38. Gibbons CH, Freeman R (2015) Clinical implications of delayed orthostatic hypotension: A 10-year follow-up study. Neurology. doi:10.1212/WNL.0000000000002030

39. Low PA, Tomalia VA, Park KJ (2013) Autonomic function tests: some clinical applications. J Clin Neurol 9(1):1-8. doi:10.3988/ jen.2013.9.1.1

40. Baschieri F, Calandra-Buonaura G, Doria A, Mastrolilli F, Palareti A, Barletta G, Solieri L, Guaraldi P, Martinelli P, Cortelli P (2015) Cardiovascular autonomic testing performed with a new integrated instrumental approach is useful in differentiating MSA-P from PD at an early stage. Parkinsonism Relat Disord 21(5):477-482. doi:10.1016/j.parkreldis.2015.02.011

41. Goldstein DS, Holmes C, Sharabi Y, Brentzel S, Eisenhofer G (2003) Plasma levels of catechols and metanephrines in neurogenic orthostatic hypotension. Neurology 60(8):1327-1332

42. Robertson D (2008) The pathophysiology and diagnosis of orthostatic hypotension. Clin Auton Res Off J Clin Auton Res Soc 18(Suppl 1):2-7

43. Freeman R (2003) Treatment of orthostatic hypotension. Semin Neurol 23(4):435-442

44. Weinberg AD, Minaker KL (1995) Dehydration:evaluation and management in older adults. Council on Scientific Affairs, American Medical Association. J Am Med Assoc 274(19):1552-1556

45. Jordan J, Shannon JR, Black BK, Ali Y, Farley M, Costa F, Diedrich A, Robertson RM, Biaggioni I, Robertson D (2000) The pressor response to water drinking in humans: a sympathetic reflex? Circulation 101(5):504-509

46. Shannon JR, Diedrich A, Biaggioni I, Tank J, Robertson RM, Robertson D, Jordan J (2002) Water drinking as a treatment for orthostatic syndromes. Am J Med 112(5):355-360
47. May M, Jordan J (2011) The osmopressor response to water drinking. Am J Physiol Regul Integr Comp Physiol 300(1):R40 R46. doi:10.1152/ajpregu.00544.2010

48. Lipp A, Tank J, Franke G, Arnold G, Luft FC, Jordan J (2005) Osmosensitive mechanisms contribute to the water drinking-induced pressor response in humans. Neurology 65(6):905-907. doi:10.1212/01.wnl.0000176060.90959.36

49. Raj SR, Biaggioni I, Black BK, Rali A, Jordan J, Taneja I, Harris PA, Robertson D (2006) Sodium paradoxically reduces the gastropressor response in patients with orthostatic hypotension. Hypertension 48(2):329-334. doi:10.1161/01.HYP.0000229906. $27330.4 \mathrm{f}$

50. Schroeder C, Bush VE, Norcliffe LJ, Luft FC, Tank J, Jordan J, Hainsworth R (2002) Water drinking acutely improves orthostatic tolerance in healthy subjects. Circulation 106(22):2806-2811

51. Jordan J, Shannon JR, Diedrich A, Black B, Robertson D, Biaggioni I (2004) Water potentiates the pressor effect of ephedra alkaloids. Circulation 109(15):1823-1825

52. Mathias CJ, Young TM (2004) Water drinking in the management of orthostatic intolerance due to orthostatic hypotension, vasovagal syncope and the postural tachycardia syndrome. Eur J Neurol 11(9):613-619

53. Claydon VE, Schroeder C, Norcliffe LJ, Jordan J, Hainsworth R (2006) Water drinking improves orthostatic tolerance in patients with posturally related syncope. Clin Sci 110(3):343-352

54. Kerstens MN, Kobold AC, Volmer M, Koerts J, Sluiter WJ, Dullaart RP (2011) Reference Values for Aldosterone-Renin Ratios in Normotensive Individuals and Effect of Changes in Dietary Sodium Consumption. Clin Chem 57(11):1607-1611. doi:10.1373/clinchem.2011.165662

55. Mtinangi BL, Hainsworth R (1998) Early effects of oral salt on plasma volume, orthostatic tolerance, and baroreceptor sensitivity in patients with syncope. Clin Auton Res Off J Clin Auton Res Soc 8(4):231-235

56. Baas SJ, Endert E, Fliers E, Prummel MF, Wiersinga WM (2003) Establishment of reference values for endocrine tests. III: primary aldosteronism. The Netherlands J Med 61(2):37-43

57. Kranzler HR, Cardoni A (1988) Sodium chloride treatment of antidepressant-induced orthostatic hypotension. J Clin Psychiatry 49:366-368

58. Smith GD, Mathias CJ (1995) Postural hypotension enhanced by exercise in patients with chronic autonomic failure. QJM 88(4):251-256

59. Zion AS, De Meersman R, Diamond BE, Bloomfield DM (2003) A home-based resistance-training program using elastic bands for elderly patients with orthostatic hypotension. Clin Auton Res Off J Clin Auton Res Soc 13(4):286-292. doi:10.1007/s10286-0030117-3

60. Figueroa JJ, Basford JR, Low PA (2010) Preventing and treating orthostatic hypotension: as easy as A, B, C. Cleve Clin J Med 77(5):298-306. doi:10.3949/ccjm.77a.09118

61. Pierangeli G, Provini F, Maltoni P, Barletta G, Contin M, Lugaresi E, Montagna P, Cortelli P (2001) Nocturnal body core temperature falls in Parkinson's disease but not in MultipleSystem Atrophy. Mov Disord 16(2):226-232

62. Wieling W, van Lieshout JJ, van Leeuwen AM (1993) Physical manoeuvres that reduce postural hypotension in autonomic failure. Clin Auton Res Off J Clin Auton Res Soc 3(1):57-65

63. ten Harkel AD, van Lieshout JJ, Wieling W (1992) Treatment of orthostatic hypotension with sleeping in the head- up tilt position, alone and in combination with fludrocortisone. J Intern Med 232(2):139-145

64. Henry R, Rowe J, O’Mahony D (1999) Haemodynamic analysis of efficacy of compression hosiery in elderly fallers with orthostatic hypotension [letter]. Lancet 354(9172):45-46 
65. Denq JC, Opfer-Gehrking TL, Giuliani M, Felten J, Convertino VA, Low PA (1997) Efficacy of compression of different capacitance beds in the amelioration of orthostatic hypotension. Clin Auton Res Off J Clin Auton Res Soc 7(6):321-326

66. Smit AA, Wieling W, Fujimura J, Denq JC, Opfer-Gehrking TL, Akarriou M, Karemaker JM, Low PA (2004) Use of lower abdominal compression to combat orthostatic hypotension in patients with autonomic dysfunction. Clin Auton Res Off J Clin Auton Res Soc 14(3):167-175

67. Okamoto LE, Diedrich A, Baudenbacher FJ, Harder R, Whitfield JS, Iqbal F, Gamboa A, Shibao CA, Black BK, Raj SR, Robertson D, Biaggioni I (2016) Efficacy of Servo-Controlled Splanchnic Venous Compression in the Treatment of Orthostatic Hypotension: A Randomized Comparison With Midodrine. Hypertension. doi:10.1161/hypertensionaha.116.07199

68. Jansen RW, Lipsitz LA (1995) Postprandial hypotension: epidemiology, pathophysiology, and clinical management. Ann Intern Med 122(4):286-295

69. Puisieux F, Boumbar Y, Bulckaen H, Bonnin E, Houssin F, Dewailly P (1999) Intraindividual variability in orthostatic blood pressure changes among older adults: the influence of meals. J Am Geriatr Soc 47(11):1332-1336

70. Puvi-Rajasingham S, Mathias CJ (1996) Effect of meal size on post-prandial blood pressure and on postural hypotension in primary autonomic failure. Clin Auton Res Off J Clin Auton Res Soc 6(2):111-114

71. Berry MK, Russo A, Wishart JM, Tonkin A, Horowitz M, Jones KL (2003) Effect of solid meal on gastric emptying of, and glycemic and cardiovascular responses to, liquid glucose in older subjects. Am J Physiol Gastrointest Liv Physiol 284(4):G655G662. doi:10.1152/ajpgi.00163.2002

72. Jansen RW, Peeters TL, Van Lier HJ, Hoefnagels WH (1990) The effect of oral glucose, protein, fat and water loading on blood pressure and the gastrointestinal peptides VIP and somatostatin in hypertensive elderly subjects. Eur J Clin Invest 20(2):192-198

73. Onrot J, Goldberg MR, Biaggioni I, Hollister AS, Kingaid D, Robertson D (1985) Hemodynamic and humoral effects of caffeine in autonomic failure. Therapeutic implications for postprandial hypotension. N Engl J Med 313(9):549-554. doi:10. 1056/nejm198508293130905

74. Shibao C, Gamboa A, Diedrich A, Dossett C, Choi L, Farley G, Biaggioni I (2007) Acarbose, an alpha-glucosidase inhibitor, attenuates postprandial hypotension in autonomic failure. Hypertension 50(1):54-61. doi:10.1161/hypertensionaha.107. 091355
75. Ando Y, Asahara K, Obayashi K, Suhr O, Yonemitsu M, Yamashita T, Tashima K, Uchino M, Ando M (1996) Autonomic dysfunction and anemia in neurologic disorders. J Auton Nerv Syst 61(2):145-148

76. Beitzke M, Pfister P, Fortin J, Skrabal F (2002) Autonomic dysfunction and hemodynamics in vitamin B12 deficiency. Auton Neurosci 97(1):45-54

77. Skrabal F (2004) Syncope, falls and cobalamin deficiency in the old population. Clin Auton Res Off J Clin Auton Res Soc 14(2):60-66. doi:10.1007/s10286-004-0179-x

78. Parsaik AK, Singh B, Altayar O, Mascarenhas SS, Singh SK, Erwin PJ, Murad MH (2013) Midodrine for orthostatic hypotension: a systematic review and meta-analysis of clinical trials. J Gen Intern Med 28(11):1496-1503. doi:10.1007/s11606013-2520-3

79. McClellan KJ, Wiseman LR, Wilde MI (1998) Midodrine. A review of its therapeutic use in the management of orthostatic hypotension. Drugs Aging 12(1):76-86

80. Kaufmann H, Saadia D, Voustianiouk A, Goldstein DS, Holmes C, Yahr MD, Nardin R, Freeman R (2003) Norepinephrine precursor therapy in neurogenic orthostatic hypotension. Circulation 108(6):724-728. doi:10.1161/01.cir.0000083721.49847.d7

81. Campbell IW, Ewing DJ, Clarke BF (1975) 9-Alpha-fluorohydrocortisone in the treatment of postural hypotension in diabetic autonomic neuropathy. Diabetes 24:381-384

82. Decaux G (1979) Fludrocortisone in orthostatic hypotension [letter]. N Engl J Med 301:1121-1122

83. Watt SJ, Tooke JE, Perkins CM, Lee MR (1981) The treatment of idiopathic orthostatic hypotension: a combined fludrocortisone and flurbiprofen regime. Q J Med 50:205-212

84. van Lieshout JJ, ten Harkel AD, Wieling W (2000) Fludrocortisone and sleeping in the head-up position limit the postural decrease in cardiac output in autonomic failure. Clin Auton Res Off J Clin Auton Res Soc 10(1):35-42

85. James PA, Oparil S, Carter BL, Cushman WC, Dennison-Himmelfarb C, Handler J, Lackland DT, LeFevre ML, MacKenzie TD, Ogedegbe O, Smith Jr SC, Svetkey LP, Taler SJ, Townsend RR, Wright Jr JT, Narva AS, Ortiz E (2014) 2014 evidence-based guideline for the management of high blood pressure in adults: report from the panel members appointed to the Eighth Joint National Committee (JNC 8). JAMA 311(5):507-520. doi:10. 1001/jama.2013.284427

86. Jordan J, Biaggioni I (2002) Diagnosis and treatment of supine hypertension in autonomic failure patients with orthostatic hypotension. J Clin Hypertens (Greenwich) 4(2):139-145 